\title{
Karyomorphology of Caesalpinia Species (Caesalpinioideae: Fabaceae) from Caatinga and Mata Atlantica Biomes of Brazil
}

\author{
Polliana Silva Rodrigues ${ }^{1}$, Margarete Magalhães Souza ${ }^{2} \&$ Ronan Xavier Corrêa ${ }^{2}$ \\ ${ }^{1}$ Programa de Pós-Graduação em Genética e Biologia Molecular, Universidade Estadual de Santa Cruz, Brazil \\ ${ }^{2}$ Departamento de Ciências Biológicas, Universidade Estadual de Santa Cruz, Brazil \\ Correspondence: Ronan Xavier Corrêa, Genética e Biologia Molecular, Universidade Estadual de Santa Cruz, \\ Brazil. Tel: 55-733-680-5183. E-mail: ronanxc@uesc.br
}

Received: November 29, 2011 Accepted: December 12, 2011 Online Published: August 10, 2012

doi:10.5539/jps.v1n2p82

URL: http://dx.doi.org/10.5539/jps.v1n2p82

This research was supported by Conselho Nacional de Desenvolvimento Cientifico (CNPq) (grants numbers CNPq 620147/2004-0 and 473393/2007-7). P.S.R. was awarded MSc. Fellowships from Fundação de Amparo à Pesquisa no Estado da Bahia (FAPESB) and Coordenação de Aperfeiçoamento de Pessoal de Nivel Superior (CAPES)

\begin{abstract}
Out of 140 Caesalpinia s.l. species, only 20 species have the chromosome numbers presently known, and nine species have the karyomorphological studies available. We determine the karyotype and the chromosome morphometry in five Caesalpinia s.l. spp., and we describe the heterochromatin pattern in four of them. The diploid chromosome number of 24 was reported for the first time in Caesalpinia calycina, Caesalpinia microphylla and Caesalpinia pluviosa var. peltophoroides, and confirmed in Caesalpinia ferrea var. leiostachya and Caesalpinia pulcherrima. Different karyotype formulae were obtained for each of these five species. The chromosome asymmetry index varied from $34.94 \%$ in C. pluviosa to $39.45 \%$ in C. ferrea. The average chromosome length among the five species differed significantly $(P<0.010)$. The heterochromatin blocks were evidenced by C-banding in both terminal and proximal regions of the Caesalpinia spp. chromosomes. This study represents a contribution toward an increased knowledge on cytogenetics and evolution of this genus.
\end{abstract}

Keywords: c-banding, cytogenetics, chromosome, evolution, karyotype

\section{Introduction}

Caesalpinia L. s.l. is comprised of approximately 140 species and belongs to Fabaceae, a plant family with the third largest number of known species (Lewis et al., 2005). Several Caesalpinia species suffer from the anthropogenic fragmentation of their ecosystems. For instance, six species of Caesalpinia from different countries are at risk of extinction as defined by the IUCN Red List of Threatened Species (IUCN, 2011). Among them, Caesalpinia echinata Lam. is endemic to the humid Atlantic forest along Brazil's eastern coastline and is listed as "endangered" (Varty, 1998; IUCN, 2011).

Caesalpinia s.l. has been analyzed phylogenetically by different approaches. The taxonomic studies have demonstrated that Caesalpinia s.l. is not a natural group, but rather is comprised of about 10 genera (Lewis et al., 2005; Gasson et al., 2009). Cytogenetic studies are of vital importance within systematics and elucidate phylogenetic and evolutionary relationships among groups of plants (Sumner, 2003; Biondo et al., 2005). Yet, the cytogenetics approach is still incipient in Caesalpinia s.l. and the chromosome numbers of about 20 species has been reported (Goldblatt, 1981; Cangiano \& Bernardello, 2005). Of those, only nine species have also undergone detailed karyomorphological studies (Kumari \& Bir, 1989; Cangiano \& Bernardello, 2005). The haploid chromosome numbers $(n)$ of 12 and diploid chromosome numbers (2n) of 24 are common in this group, although polyploidy has been detected in Caesalpinia ferrea Mart. ex Tul. var. leiostachya Benth. $(2 n=24$ e 48$)$ and Caesalpinia bracteosa Tul. $(2 n=48)$ (Alves \& Custodio, 1989).

Cytogenetic analyses, as a description of chromosome number and size, as well as the banding pattern and position of the centromere, frequently contribute to the understanding of evolution in plants (Shan et al., 2003) and to the elucidation of factors that have been involved in the evolutionary diversification of the taxon (Pedrosa 
et al., 2000; Vilatersana et al., 2000). In this work, the karyotypic constitution, the morphometry of the chromosomes and the heterochromatin distribution based on conventional coloration and C-banding were investigated in five species of Caesalpinia s.l. that occur in the state of Bahia, Brazil. The cytogenetic information obtained here will be useful for future studies of chromosome evolution in Caesalpinia s.l.

\section{Material and Methods}

Fruit of Caesalpinia pluviosa DC. var. peltophoroides (Benth.) G.P.Lewis, C. ferrea var. leiostachya, Caesalpinia pulcherrima Sw., Caesalpinia microphylla Mart. and Caesalpinia calycina Benth. were collected from January to April, 2007, in the state of Bahia, Brazil, respectively in the following municipalities: Itapetinga $\left(15^{\circ} 15^{\prime} 03.15^{\prime} \mathrm{S}, 40^{\circ} 14^{\prime} 59.38^{\prime}\right.$ W), Itabuna $\left(14^{\circ} 47^{\prime} 24.58^{\prime} \mathrm{S}, 3^{\circ} 14^{\prime} 54.35^{\prime \prime} \mathrm{W}\right)$, Ilhéus $\left(14^{\circ} 48^{\prime} 03.09^{\prime} \mathrm{S}\right.$,

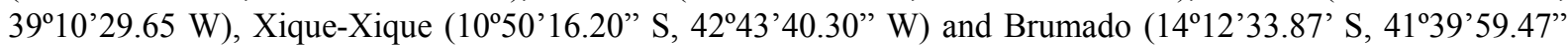
W). The first three species are typically found in the Brazilian Atlantic rainforest (Mata Atlantica Brazilian biome) and the last two in the Brazilian savanna (Caatinga). These five species were selected due to the availability of flowering materials in the visited sites. These sites were designated based on records regarding the occurrence of the aforementioned plant species found at the CEPLAC Herbarium. As with most of the Caesalpinia species, these species have been included in different reinstated genera (Lewis et al., 2005; Gasson et al., 2009). However, in this work, we use the species nomenclature available at the IPNI (2011) for practical reasons. The botanical material was herborized and identified with the aid of analitical keys and compared with existing material in the Herbarium of Universidade Estadual de Santa Cruz (UESC), where the specimens are deposited.

Seeds were treated with the fungicide Captan Fersol for $24 \mathrm{~h}$ and germinated at $24{ }^{\circ} \mathrm{C}$ in Petri dishes covered with filter paper moistened with distilled water. Tips of roots measuring $1-2 \mathrm{~cm}$ of length were pre-treated in 8-hydroxyquinoline $\left(0.002 \mathrm{~mol} . \mathrm{L}^{-1}\right)$ for $6 \mathrm{~h}\left(1 \mathrm{~h}\right.$ at $24{ }^{\circ} \mathrm{C}$ and $5 \mathrm{~h}$ at $\left.4{ }^{\circ} \mathrm{C}\right)$. Samples were fixed in Carnoy I (ethanol/acetic acid 3:1, v:v) for $3 \mathrm{~h}$ at $24{ }^{\circ} \mathrm{C}$ and later stored at $-20{ }^{\circ} \mathrm{C}$. Roots were washed twice in distilled water ( 5 min each) and incubated in a solution containing cellulase $(2 \%, \mathrm{w} / \mathrm{v})$ and pectinase $(20 \%, \mathrm{w} / \mathrm{v})$ at 37 ${ }^{\circ} \mathrm{C}$ for $1 \mathrm{~h}$ in a humidity chamber. Subsequently, one drop of acetic acid $(45 \%, \mathrm{w} / \mathrm{v})$ was added to the roots for 5 min. The slides were prepared through maceration (Guerra and Souza 2002). The slides were immersed in liquid $\mathrm{N}_{2}$ after the removal of coverslips and stored at $-20^{\circ} \mathrm{C}$.

For karyotype analysis, the slides were dried at room temperature $\left(24^{\circ} \mathrm{C}\right)$ and stained with Giemsa $(2 \%$, w/v) for $10 \mathrm{~min}$, then rinsed in distilled water and dried again at room temperature and mounted in Neo-Mount ${ }^{\circledR}$ (Merck, Darmstadt, Germany). For the study of the heterochromatin pattern, the previously prepared slides were treated according to Guerra and Souza (2002) protocol, with the following adaptations: the chromosomes of $C$. pluviosa var. peltophoroides, C. ferrea var. leiostachya and C. calycina were denaturated for $100 \mathrm{~min}$ and the chromosomes of C. ferrea var. leiostachya and C. pluviosa var. peltophoroides were stained for $45 \mathrm{~min}$. The slides containing the metaphases and the micrometric slide were photographed using a BX51 microscope equipped with a C-7070 digital camera (Olympus, Tokyo, Japan).

Chromosome measurements were carried out in five metaphases of each species using Adobe Photoshop ${ }^{\circledR}$ CS3 version 10.0 for the following parameters: short arm length (S), long arm length $(\mathrm{L})$, and absolute chromosome length (A). We used the averages of chromosome measurements to construct ideograms: to calculate the haploid karyotype length $(\mathrm{KL}=$ total length of all chromosomes $\div 2)$, relative chromosome length $(\mathrm{RCL} \%=$ [total length of each chromosome $\div \mathrm{KL}] \times 100)$, average chromosome length $\left(\mathrm{C}=\sum\right.$ of the total length of all chromosomes $\div$ diploid chromosome number), ratio between arms $(\mathrm{r}=$ long arm length $\div$ short arm length), and chromosome asymmetry index (A2 $=\left[\sum\right.$ of the short arms lengths $\div$ haploid karyotype length $\left.] \mathrm{x} 100\right)$ (Huziwara, 1962). Karyotypes were classified according to the position of the centromere following Levan et al. (1964). Satellites were classified according to Battaglia's terminology (1955). The length of the satellites was not added to the length of the corresponding chromosome arm but was added to the total length of the chromosome (Cuco et al., 2003).

We used an entirely random delineation for the evaluation of intra and inter-specific karyotype variations. Chromosome length data were analyzed using ANOVA, and differences between averages were analyzed by Tukey's test $(P<0.01)$ using the software GENES version 2009.7.0 (Cruz, 2006).

\section{Results}

The diploid chromosome number of for all species analyzed was 24 (Figure 1). The five studied species showed distinct features that were revealed by the morphometric analysis (Table 1). Statistical analyses showed significant differences $(\mathrm{P}<0.01)$ in chromosome length (Table 2$)$, which indicates variation in genome size. The variance analysis showed significant difference $(\mathrm{P}<0.01)$ among chromosome pairs in each analyzed species 
(Table 3). Also, there was significant difference in chromosome length among the species for each chromosome pair (Table 4). For all of the statistical analyses, the coefficients of variation (CV) were low (10.8\% on average); thus the measurements showed good replicability and the sample size was adequate for the study.

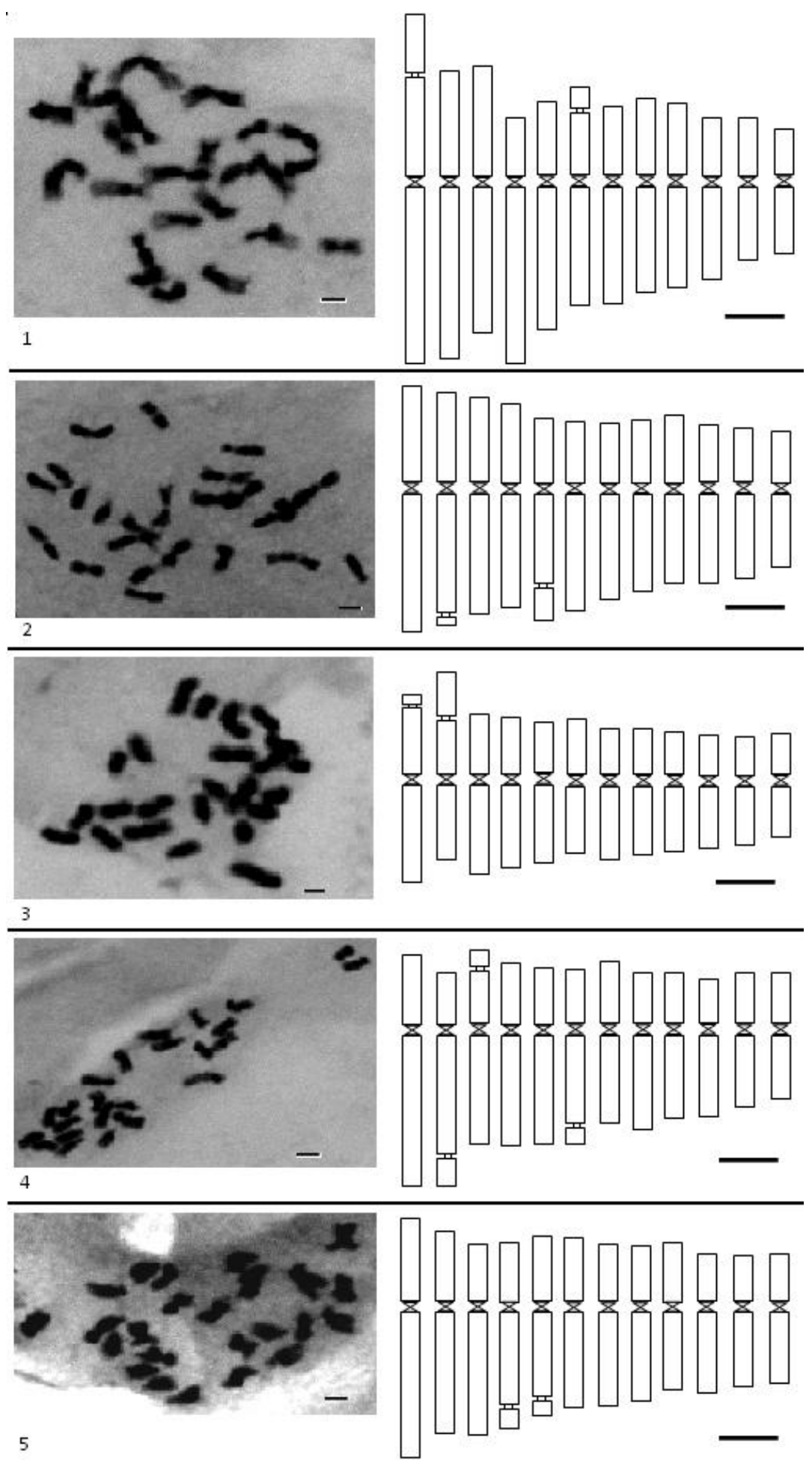

Figure 1. Mitotic metaphase chromosomes $(\mathrm{bar}=10 \mu \mathrm{m})$ and ideogram $(\mathrm{bar}=1 \mu \mathrm{m})$ of $C$. calycina $(1)$; $C$. ferrea var. leiostachya (2); C. microphylla (3); C. pluviosa var. peltophoroides (4); C. pulcherrima (5). 
Table 1. Chromosome morphometry of Caesalpinia species. Averages of the short arm length (S), long arm length (L), satellite size (SAT), total length of the chromosomes (C), relative chromosome length (RCL \%), and ratio between arms ( $\mathrm{r})$. Nomenclature for chromosome (Chrom) morphology $(\mathrm{N}$ : $\mathrm{M}=$ Metacentric, $1.00 \leq \mathrm{r} \leq$ 1.66; $\mathrm{SM}=$ Submetacentric, $1.67 \leq \mathrm{r} \leq 2.99 ; \mathrm{ST}=$ Subtelocentric, $3.00 \leq \mathrm{r} \leq 6.99$ )

\begin{tabular}{|c|c|c|c|c|c|c|c|c|}
\hline \multirow[t]{2}{*}{ Species } & \multirow[t]{2}{*}{ Chrom } & \multicolumn{7}{|c|}{ Average Value } \\
\hline & & $\mathrm{S}(\mu \mathrm{m})$ & $\mathrm{L}(\mu \mathrm{m})$ & SAT $(\mu \mathrm{m})$ & $\mathrm{C}(\mu \mathrm{m})^{*}$ & RCL (\%) & $\mathrm{r}$ & $\mathrm{N}$ \\
\hline \multirow[t]{12}{*}{ C. calycina } & 1 & $1.60 \pm 0.58$ & $2.87 \pm 0.72$ & $0.95 \pm 0.22$ & $5.43 \pm 0.63 \mathrm{a}$ & 13.6 & 1.79 & SM \\
\hline & 2 & $1.70 \pm 0.40$ & $2.79 \pm 0.15$ & - & $4.49 \pm 0.28 \mathrm{ab}$ & 11.3 & 1.63 & $\mathrm{M}$ \\
\hline & 3 & $1.79 \pm 0.22$ & $2.38 \pm 0.19$ & - & $4.17 \pm 0.41 b c$ & 10.5 & 1.33 & $\mathrm{M}$ \\
\hline & 4 & $0.93+0.19$ & $2.87+0.17$ & - & $3.81+0.24 \mathrm{bcd}$ & 9.6 & 3.07 & ST \\
\hline & 5 & $1.18 \pm 0.27$ & $2.33 \pm 0.27$ & - & $3.51 \pm 0.30 \mathrm{cde}$ & 8.8 & 1.97 & SM \\
\hline & 6 & $0.98 \pm 0.09$ & $1.91 \pm 0.58$ & $0.35 \pm 0.10$ & $3.25 \pm 0.41 \mathrm{def}$ & 8.2 & 1.93 & SM \\
\hline & 7 & $1.11 \pm 0.22$ & $1.88 \pm 0.35$ & - & $3.00 \pm 0.15 \mathrm{ef}$ & 7.5 & 1.69 & $\mathrm{M}$ \\
\hline & 8 & $1.22 \pm 0.16$ & $1.71 \pm 0.15$ & - & $2.94 \pm 0.99 \mathrm{efg}$ & 7.4 & 1.39 & $\mathrm{M}$ \\
\hline & 9 & $1.15 \pm 0.21$ & $1.64 \pm 0.19$ & - & $2.80 \pm 0.14 \mathrm{efg}$ & 7.0 & 1.42 & $\mathrm{M}$ \\
\hline & 10 & $0.94 \pm 0.17$ & $1.50 \pm 0.33$ & - & $2.46 \pm 0.29 \mathrm{fgh}$ & 6.2 & 1.59 & $\mathrm{M}$ \\
\hline & 11 & $0.96 \pm 0.06$ & $1.19 \pm 0.11$ & - & $2.15 \pm 0.15 \mathrm{gh}$ & 5.4 & 1.24 & M \\
\hline & 12 & $0.73 \pm 0.06$ & $1.07 \pm 0.18$ & - & $1.81 \pm 0.15 \mathrm{~h}$ & 4.5 & 1.47 & M \\
\hline C. ferrea var. & 1 & $1.57 \pm 0.17$ & $2.25 \pm 0.38$ & - & $3.82 \pm 0.38 \mathrm{a}$ & 11.1 & 1.45 & $\mathrm{M}$ \\
\hline \multirow[t]{11}{*}{ leiostachya } & 2 & $1.46 \pm 0.20$ & $1.93 \pm 0.20$ & $0.14 \pm 0.11$ & $3.54 \pm 0.26 \mathrm{ab}$ & 10.3 & 1.34 & $\mathrm{M}$ \\
\hline & 3 & $1.37 \pm 0.38$ & $1.97 \pm 0.27$ & - & $3.34 \pm 0.25 a b c$ & 9.7 & 1.62 & $\mathrm{M}$ \\
\hline & 4 & $1.33 \pm 0.19$ & $1.86 \pm 0.17$ & - & $3.20 \pm 0.20 \mathrm{abcd}$ & 9.3 & 1.42 & $\mathrm{M}$ \\
\hline & 5 & $1.05 \pm 0.31$ & $1.46 \pm 0.31$ & $0.52 \pm 0.17$ & $3.05 \pm 0.28 \mathrm{bcd}$ & 8.8 & 1.42 & $\mathrm{M}$ \\
\hline & 6 & $1.00 \pm 0.35$ & $1.92 \pm 0.29$ & - & $3.92 \pm 0.28$ bcde & 8.4 & 2.16 & SM \\
\hline & 7 & $0.99 \pm 0.32$ & $1.73 \pm 0.34$ & - & $2.73 \pm 0.26 \mathrm{cdef}$ & 7.9 & 2.00 & SM \\
\hline & 8 & $1.02 \pm 0.31$ & $1.58 \pm 0.29$ & - & $2.61 \pm 0.20 \mathrm{defg}$ & 7.6 & 1.74 & SM \\
\hline & 9 & $1.12 \pm 0.13$ & $1.45 \pm 0.10$ & - & $2.58+0.19 \mathrm{defg}$ & 7.5 & 1.30 & $\mathrm{M}$ \\
\hline & 10 & $0.93 \pm 0.16$ & $1.45 \pm 0.26$ & - & $2.38 \pm 0.22 \mathrm{efg}$ & 6.9 & 1.62 & $\mathrm{M}$ \\
\hline & 11 & $0.88 \pm 0.25$ & $1.38 \pm 0.20$ & - & $2.27 \pm 0.21 \mathrm{fg}$ & 6.6 & 1.75 & SM \\
\hline & 12 & $0.84 \pm 0.13$ & $1.21 \pm 0.14$ & - & $2.05 \pm 0.19 \mathrm{~g}$ & 5.9 & 1.46 & $\mathrm{M}$ \\
\hline$C$. & 1 & $1.09 \pm 0.12$ & $1.57 \pm 0.34$ & $0.16 \pm 0.06$ & $2.83 \pm 0.36 \mathrm{a}$ & 11.5 & 1.44 & $\mathrm{M}$ \\
\hline \multirow[t]{11}{*}{ microphylla } & 2 & $0.86 \pm 0.23$ & $1.22 \pm 0.19$ & $0.70 \pm 0.07$ & $2.79 \pm 0.38 \mathrm{ab}$ & 11.4 & 1.40 & $\mathrm{M}$ \\
\hline & 3 & $0.98+0.06$ & $1.45 \pm 0.16$ & - & $2.43 \pm 0.22 \mathrm{abc}$ & 9.9 & 1.48 & $\mathrm{M}$ \\
\hline & 4 & $0.91 \pm 0.28$ & $1.35 \pm 0.14$ & - & $2.27 \pm 0.27 \mathrm{abcd}$ & 9.2 & 1.47 & M \\
\hline & 5 & $0.82 \pm 0.12$ & $1.27 \pm 0.31$ & - & $2.09 \pm 0.31 \mathrm{bcde}$ & 8.5 & 1.55 & $\mathrm{M}$ \\
\hline & 6 & $0.89 \pm 0.09$ & $1.09 \pm 0.18$ & - & $1.98 \pm 0.24$ bcde & 8.1 & 1.23 & $\mathrm{M}$ \\
\hline & 7 & $0.73+0.14$ & $1.18 \pm 0.14$ & - & $1.91 \pm 0.23 \mathrm{cde}$ & 7.8 & 1.62 & $\mathrm{M}$ \\
\hline & 8 & $0.73 \pm 0.14$ & $1.10 \pm 0.15$ & - & $1.84 \pm 0.24 \mathrm{cde}$ & 7.5 & 1.51 & M \\
\hline & 9 & $0.67 \pm 0.16$ & $1.06 \pm 0.14$ & - & $1.74 \pm 0.25 \mathrm{de}$ & 7.1 & 1.56 & $\mathrm{M}$ \\
\hline & 10 & $0.66 \pm 0.13$ & $0.99 \pm 0.09$ & - & $1.65 \pm 0.15 \mathrm{de}$ & 6.7 & 1.50 & M \\
\hline & 11 & $0.62 \pm 0.16$ & $0.94 \pm 0.12$ & - & $1.57 \pm 0.20 \mathrm{e}$ & 6.4 & 1.51 & $\mathrm{M}$ \\
\hline & 12 & $0.65 \pm 0.05$ & $0.82 \pm 0.14$ & - & $1.47 \pm 0.16 \mathrm{e}$ & 5.9 & 1.26 & $\mathrm{M}$ \\
\hline C. pluviosa & 1 & $1.13 \pm 0.16$ & $2.46 \pm 0.36$ & - & $3.59 \pm 0.46 \mathrm{a}$ & 11.6 & 2.17 & SM \\
\hline & 2 & $0.85 \pm 0.09$ & $1.94 \pm 0.77$ & $0.46 \pm 0.14$ & $3.26 \pm 0.35 \mathrm{ab}$ & 10.6 & 2.33 & SM \\
\hline peltophoroide & 3 & $0.86 \pm 0.27$ & $1.79 \pm 0.35$ & $0.27 \pm 0.07$ & $2.93 \pm 0.31 \mathrm{bc}$ & 9.5 & 2.14 & SM \\
\hline \multirow[t]{9}{*}{$s$} & 4 & $1.02 \pm 0.21$ & $1.80 \pm 0.06$ & - & $2.83 \pm 0.23 \mathrm{bcd}$ & 9.2 & 1.81 & SM \\
\hline & 5 & $0.94 \pm 0.24$ & $1.79 \pm 0.10$ & - & $2.73 \pm 0.26 \mathrm{cde}$ & 8.9 & 1.99 & SM \\
\hline & 6 & $0.87 \pm 0.18$ & $1.45 \pm 0.18$ & $0.25 \pm 0.03$ & $2.58 \pm 0.33 \mathrm{def}$ & 8.4 & 1.67 & $\mathrm{M}$ \\
\hline & 7 & $1.01 \pm 0.12$ & $1.43 \pm 0.19$ & - & $2.45 \pm 0.29$ ef & 7.9 & 1.40 & M \\
\hline & 8 & $0.82 \pm 0.14$ & $1.53 \pm 0.28$ & - & $2.36 \pm 0.30 \mathrm{efg}$ & 7.6 & 1.89 & SM \\
\hline & 9 & $0.83 \pm 0.21$ & $1.35 \pm 0.14$ & - & $2.19 \pm 0.17 \mathrm{efg}$ & 7.1 & 1.75 & SM \\
\hline & 10 & $0.73 \pm 0.10$ & $1.32 \pm 0.14$ & - & $2.06 \pm 0.20 \mathrm{fgh}$ & 6.7 & 1.82 & SM \\
\hline & 11 & $0.84 \pm 0.14$ & $1.18 \pm 0.14$ & - & $2.01 \pm 0.21 \mathrm{gh}$ & 6.5 & 1.42 & $\mathrm{M}$ \\
\hline & 12 & $0.83 \pm 0.11$ & $1.04 \pm 0.10$ & - & $1.87 \pm 0.19 \mathrm{~h}$ & 6.0 & 1.26 & $\mathrm{M}$ \\
\hline$C$. & 1 & $1.35 \pm 0.44$ & $2.38 \pm 0.33$ & - & $3.73 \pm 0.50 \mathrm{a}$ & 12.0 & 1.91 & SM \\
\hline \multirow[t]{11}{*}{ pulcherrima } & 2 & $1.15 \pm 0.37$ & $1.99 \pm 0.19$ & - & $3.15 \pm 0.34 \mathrm{ab}$ & 10.1 & 1.87 & SM \\
\hline & 3 & $0.94 \pm 0.23$ & $2.02 \pm 0.25$ & - & $2.96 \pm 0.20 \mathrm{abc}$ & 9.5 & 2.30 & SM \\
\hline & 4 & $0.97 \pm 0.21$ & $1.51 \pm 0.22$ & $0.31 \pm 0.04$ & $2.80 \pm 0.28 \mathrm{bcd}$ & 9.0 & 1.62 & $\mathrm{M}$ \\
\hline & 5 & $1.06 \pm 0.31$ & $1.37 \pm 0.20$ & $0.23 \pm 0.02$ & $2.67 \pm 0.35$ bcde & 8.6 & 1.35 & $\mathrm{M}$ \\
\hline & 6 & $1.03 \pm 0.22$ & $1.57 \pm 0.14$ & - & $2.61 \pm 0.29 \mathrm{bcde}$ & 8.4 & 1.57 & M \\
\hline & 7 & $0.92 \pm 0.18$ & $1.55 \pm 0.55$ & - & $2.48 \pm 0.26$ bcde & 7.9 & 1.78 & SM \\
\hline & 8 & $0.90 \pm 0.10$ & $1.45 \pm 0.37$ & - & $2.35 \pm 0.29$ bcde & 7.6 & 1.66 & M \\
\hline & 9 & $0.97 \pm 0.26$ & $1.28 \pm 0.16$ & - & $2.25 \pm 0.30 \mathrm{cde}$ & 7.3 & 1.44 & $\mathrm{M}$ \\
\hline & 10 & $0.77 \pm 0.17$ & $1.33 \pm 0.41$ & - & $2.10 \pm 0.35 \mathrm{de}$ & 6.8 & 1.84 & SM \\
\hline & 11 & $0.75 \pm 0.26$ & $1.23 \pm 0.25$ & - & $1.99 \pm 0.32 \mathrm{de}$ & 6.4 & 1.90 & SM \\
\hline & 12 & $0.77 \pm 0.19$ & $1.15 \pm 0.13$ & - & $1.93 \pm 0.31 \mathrm{e}$ & 6.2 & 1.54 & $\mathrm{M}$ \\
\hline
\end{tabular}

Averages with similar letter dont differ statistically according to the Tukey’s test $(P<0.01)$. 
Table 2. Parameters of the analysis of variance (ANOVA) for chromosomes length among five Caesalpinia: $C$. calycina, C. microphylla, C. ferrea var. leiostachya, C. pluviosa var. peltophoroides and C. pulcherrima $(2 n=$ 24)

\begin{tabular}{ccc}
\hline Source of variation & Degrees of freedom & Mean Square \\
\hline Taxa & 4 & $2.5915^{* *}$ \\
Error & 55 & $0.4223^{* *}$ \\
$\mathrm{CV}(\%)$ & & 24.21 \\
\hline
\end{tabular}

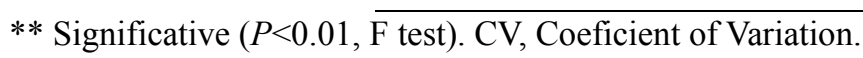

Table 3. Parameters of the analysis of variance (ANOVA) for lengths of 12 chromosome pairs within each Caesalpinia species: C. calycina (CC), C. microphylla (CM), C. ferrea var. leiostachya (CFL), C. pluviosa var. peltophoroides (CPP) and C. pulcherrima (CP) $(2 n=24 ; n=12)$

\begin{tabular}{|c|c|c|c|c|c|c|}
\hline \multirow{2}{*}{ Source of variation } & \multirow{2}{*}{ Df } & \multicolumn{5}{|c|}{ Mean Square } \\
\hline & & $\mathrm{CC}$ & $\mathrm{CM}$ & $\mathrm{CFL}$ & CPP & $\mathrm{CP}$ \\
\hline Pairs of chromosomes & 11 & $4.8874 * *$ & $1.4410 * *$ & $0.9091 * *$ & $1.3743 * *$ & $1.3720^{* *}$ \\
\hline Error & 48 & 0.0980 & 0.0647 & 0.0702 & 0.0845 & 0.1055 \\
\hline CV (\%) & & 9.53 & 8.84 & 13.01 & 11.28 & 12.54 \\
\hline
\end{tabular}

** Significative $(\mathrm{P}<0.01, \mathrm{~F}$ test $) ; \mathrm{Df}$, degrees of freedom.

Table 4. Summary of the analysis of variance (ANOVA) for chromosomes lengths pairs among Caesalpinia species: C. calycina, C. microphylla, C. ferrea var. leiostachya, C. pluviosa var. peltophoroides and $C$. pulcherrima $(2 n=24 ; n=12)$.

\begin{tabular}{|c|c|c|c|c|c|c|c|c|c|c|c|c|c|}
\hline \multirow[t]{2}{*}{$\mathrm{Sv}$} & \multirow{2}{*}{$\begin{array}{l}D \\
f\end{array}$} & \multicolumn{12}{|c|}{ Mean square } \\
\hline & & 1 & 2 & 3 & 4 & 5 & 6 & 7 & 8 & 9 & 10 & 11 & 12 \\
\hline Taxa & 4 & $\begin{array}{c}3.6294^{*} \\
*\end{array}$ & $\begin{array}{c}2.3249 * \\
*\end{array}$ & $\begin{array}{c}2.1083 * \\
*\end{array}$ & $\begin{array}{c}1.6208 * \\
*\end{array}$ & $\begin{array}{c}1.3606 * \\
*\end{array}$ & $\begin{array}{c}0.0895 * \\
*\end{array}$ & $\begin{array}{c}0.8103 * \\
*\end{array}$ & $\begin{array}{c}0.0811 * \\
*\end{array}$ & $\begin{array}{c}0.8197 * \\
*\end{array}$ & $\begin{array}{c}0.5020 * \\
*\end{array}$ & $\begin{array}{c}0.3492 * \\
*\end{array}$ & $\begin{array}{c}0.2341 * \\
*\end{array}$ \\
\hline Error & 20 & 0.2325 & 0.1094 & 0.0853 & 0.0632 & 0.0887 & 0.1020 & 0.0618 & 0.0586 & 0.0489 & 0.0658 & 0.0532 & 0.0457 \\
\hline $\begin{array}{l}\mathrm{CV}(\% \\
)\end{array}$ & & 12.60 & 9.66 & 9.21 & 8.42 & 10.58 & 12.10 & 9.88 & 9.99 & 9.55 & 12.01 & 11.53 & 11.68 \\
\hline
\end{tabular}

Table 5. Haploid karyotype length (KL), average chromosome length (C), asymmetry index (A2) and karyotipic formula $(\mathrm{KF})$ for five Caesalpinia species

\begin{tabular}{lllll}
\hline Species & $\mathrm{KL}(\mu \mathrm{m})$ & $\mathrm{C}(\mu \mathrm{m})$ & $\mathrm{A} 2(\%)$ & $\mathrm{KF}$ \\
\hline C. calycina & 39.86 & 3.32 & 36.00 & $8 \mathrm{M}+3 \mathrm{SM}+1 \mathrm{ST}$ \\
C. ferrea var. leiostachya & 34.54 & 2.87 & 39.45 & $8 \mathrm{M}+4 \mathrm{SM}$ \\
C. microphylla & 24.63 & 2.05 & 39.17 & $12 \mathrm{M}$ \\
C. pluviosa var. peltophoroides & 30.90 & 2.57 & 34.94 & $4 \mathrm{M}+8 \mathrm{SM}$ \\
C. pulcherrima & 31.07 & 2.58 & 37.44 & $6 \mathrm{M}+6 \mathrm{SM}$ \\
\hline
\end{tabular}

The most variation in chromosome length was observed in $C$. calycina and the least variation within $C$. microphylla $(\mathrm{P}<0.01)$. Chromosome pairs 8 and 9 were not significantly different either in $C$. calycina or in $C$. ferrea var. leiostachya. In $C$. pulcherrima the average chromosome length of chromosome pairs 5 , 6, 7, and 8 did not vary significantly. Except for C. calycina, the other four species showed at least one chromosome pair which was morphologically similar (Table 1 ). 
The average chromosome length varied from $3.32 \mu \mathrm{m}$ in C. calycina to $2.05 \mu \mathrm{m}$ in C. microphylla, and the haploid karyotype length varied from $39.86 \mu \mathrm{m}$ in C. calycina to $24.63 \mu \mathrm{m}$ in C. microphylla (Table 5). The karyotype formulae were characteristic for each of the species analyzed, ranging from karyotype with all chromosomes metacentric $(C$. microphylla, $\mathrm{KF}=12 \mathrm{M})$ to three different tipes of chromosomes $(C$. calycina $\mathrm{KF}=8 \mathrm{M}+3 \mathrm{SM}+1 \mathrm{ST})$. The chromosome asymmetry index in the current study varied from $\mathrm{A} 2=34.94 \%$ in $C$. pluviosa var. peltophoroides $(\mathrm{KF}=4 \mathrm{M}+8 \mathrm{SM})$ to $\mathrm{A} 2=39.45 \%$ in $C$. ferrea var. leiostachya $(\mathrm{KF}=8 \mathrm{M}+4 \mathrm{SM})$.

The relative chromosome length of each species is showed (Table 1). The RCL of chromosome pair 1 (13.63\%) of C. calycina differed considerably when compared to pair 12 (4.54 \%); whereas in C. ferrea var. leiostachya, C. microphylla, C. pluviosa var. peltophoroides, and C. pulcherrima a smaller variation was observed, with RCL ranging from 11 to $12 \%$ for pair 1 and of about $6 \%$ for pair 12 .

The satellites differed among these species regarding number, size, and chromosome location (Figure 2). In $C$. calycina, satellites were found in the short arm of pairs 1 and 6 , in C. microphylla in the short arm of chromosome pairs 1 and 2, in C. ferrea var. leiostachya in the long arm of chromosome pairs 2 and 5, in $C$. pulcherrima in the long arm of chromosome pairs 4 and 5, and in C. pluviosa var. peltophoroides in the long arm of chromosome pairs 2 and 6 as well as in the short arm of chromosome 3. The largest satellite was found in $C$. calycina $(0.95 \mu \mathrm{m})$ and the smallest in $C$. ferrea var. leiostachya $(0.14 \mu \mathrm{m})$. The satellites found in C. pluviosa var. peltophoroides were of the microsatellite type in both pair 2 and in pair 6 and were linear in pair 3 . In $C$. pulcherrima, linear satellites were found in pair 4 and microsatellites were found in pair 5 . These were different from the satellites found in C. ferrea var. leiostachya and C. microphylla, which had only satellites of the linear type, and from those in C. calycina, which were only of the microsatellite type. There was a prevalence of linear satellites compared to microsatellites in four of the five species. The exception to this pattern was C. calycina.

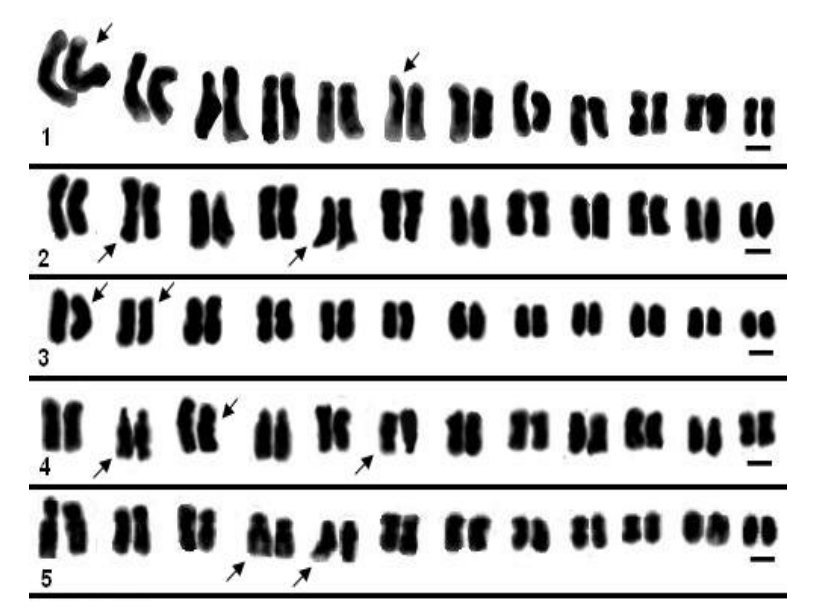

Figure 2. Karyograms of C. calycina (1); C. ferrea var. leiostachya (2); C. microphylla (3); C. pluviosa var. peltophoroides (4); C. pulcherrima (5). Arrows indicate satellites pairs. Bar $=10 \mu \mathrm{m}$

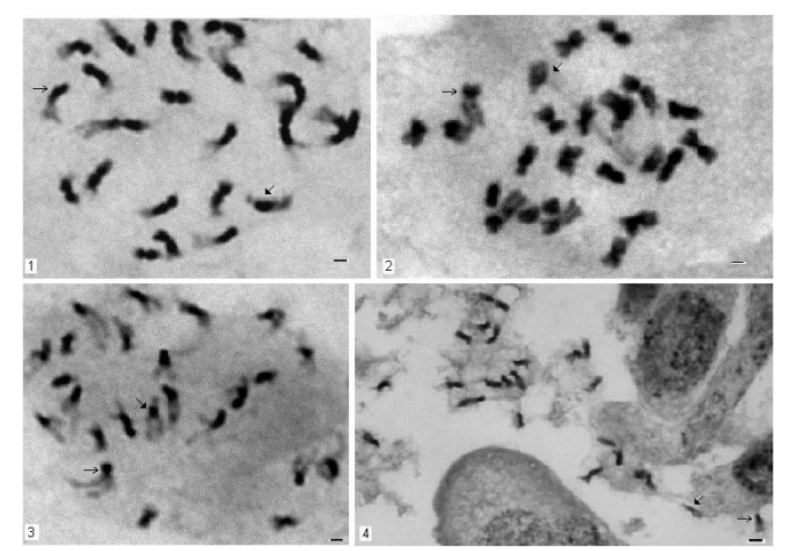

Figure 3. C-banding in C. calycina (1), C. ferrea var. leiostachya (2), C. pluviosa var. peltophoroides (3), C. pulcherrima (4), iferred as heterochromatin regions. Horizontal arrows indicate terminal C-bands and angle arrows proximal C-bands. $\mathrm{Bar}=10 \mu \mathrm{m}$ 
Terminal bands, evidenced by C-banding, were more frequent than proximal bands in all the species analyzed (Figure 3). Interstitial bands were not visualized in any of the species studied. In C. pluviosa var. peltophoroides and C. pulcherrima, small blocks of heterochromatin were observed; whereas in C. ferrea var. leiostachya and C. calycina, large blocks of heterochromatin were found. In the four of the five species studied, there was at least one pair of almost entirely heterochromatic chromosomes. C-band was not detected for C. microphylla.

\section{Discussion}

Taxonomic characterization in the genus Caesalpinia L. remains unresolved, mainly due to the difficulty in identifying the numerous species within the genus using morphological characteristics, which leads to frequent revisions in phylogenetic studies (Lewis, 1998; Gasson et al., 2009). Cytogenetic data can be useful in systematic studies. However, there is a paucity of such data for this genus. The five analyzed species had $2 \mathrm{n}=24$. This chromosome number was reported for the first time in C. pluviosa var. peltophoroides, C. calycina and C. microphylla in the present work. Additionaly, we confirmed $2 \mathrm{n}=24$ in C. pulcherrima (Atchison, 1951). We find only $2 \mathrm{n}=24$ in $C$. ferrea var. leiostachya, while $2 \mathrm{n}=24$ e $2 \mathrm{n}=48$ are related in C. ferrea (Beltrão and Guerra 1990).

The first chromosome studies carried out on Caesalpinia species revealed $2 n=24$ and $n=12$, which were considered common chromosome numbers in this group (Goldblatt, 1981). However, $2 n=24$ and $2 n=48$ were found in C. ferrea (Beltrão \& Guerra, 1990), and 2n $=48$ was found in C. bracteosa (Alves \& Custódio, 1989). These different chromosome numbers indicate the occurrence of polyploidy within the genus. Other exceptions were found for C. pulcherrima, Caesalpinia japonica Siebold and Zucc., Caesalpinia cucullata Roxb., and Caesalpinia kavaiensis H.Mann., which were initially described as having $2 \mathrm{n}=22$. This difference in the numerical pattern was attributed to mistakes in chromosome counting, both in C. pulcherrima and in C. japonica. However, $\mathrm{n}=11$ was confirmed in C. cucullata and C. kavaiensis. These latter two species were placed in the Mesoneuron genus (Lewis, 1998, Lewis et al., 2005).

Other Caesalpinia species with $2 \mathrm{n}=24$ were described: i) the $\mathrm{n}=12$ was confirmed in Caesalpinia melanadenia Standl., Caesalpinia nelsonii (Britton and Rose) J.L.Contr., Caesalpinia exostemma DC., and Caesalpinia hughesii G.P.Lewis (Goldblatt, 1981); ii) the $2 \mathrm{n}=24$ was confirmed in C. exostemma, Caesalpinia cacalaco Humb. and Bonpl., and in Caesalpinia bonduc (L.) Roxb., Caesalpinia velutina (Britton and Rose) Standl., Caesalpinia vesicaria L., Caesalpinia gilliessi (Wall. ex Hook.) Benth., Caesalpinia yucatanensis Greenm, and Caesalpinia decapetala (Roth) Alston - (Lewis, 1998); iii) the $2 \mathrm{n}=24$ was confirmed in C. gilliessi; the $2 \mathrm{n}=24$ and $\mathrm{n}=12$ were reported in Caesalpinia paraguariensis (D.Parodi) Burkart and Caesalpinia mimosifolia Griseb (Cangiano \& Bernardello, 2005); iv) the $2 \mathrm{n}=24$ also was reported in Caesalpinia crista L. (Jena et al., 2004) and Caesalpinia violaceae (Mill.) Standl. (Jarolímová, 1994).

In the current study ${ }_{2}$ the average chromosome length varied from $\mathrm{C}=3.33 \mu \mathrm{m}$ in C. calycina to $\mathrm{C}=2.05 \mu \mathrm{m}$ in C. microphylla. Cangiano and Bernardello (2005) reported C values of $1.90 \mu \mathrm{m}$ in C. gilliessi, C. paraguariensis, and C. mimosifolia. Within the Caesalpinioideae, the $C$ values reported by Auler and Battistin (1999) and Biondo et al. (2005) were equal to or inferior to $2.0 \mu \mathrm{m}$. The haploid karyotype length obtained in our study varied from $39.86 \mu \mathrm{m}$ in C. calycina to $24.63 \mu \mathrm{m}$ in C. microphylla. In other species of Caesalpinia l.s., this trait ranges from $20.67 \mu \mathrm{m}$ in C. mimosifolia to $24.74 \mu \mathrm{m}$ in C. gilliesii (Cangiano \& Bernardello, 2005). This shows a continuum between Brazilian and Argentinean species, while the larger haploid karyotype lengths were found in Brazilian species.

The chromosome asymmetry index in the current study indicates that $C$. ferrea var. leiostachya has the most ancestral condition of the karyotype (A2 $=39.45 \%$ ) while $C$. pluviosa var. peltophoroides has the most derived condition $(\mathrm{A} 2=34.94 \%)$ among the five species studied. In spite of $C$. ferrea var. leiostachya having the largest A2 value, this index did not vary considerably between C. pulcherrima $(\mathrm{A} 2=37.44 \%)$ and C. calycina $(\mathrm{A} 2=$ $36 \%$ ). The Argentinean species of Caesalpinia 1.s. have A2 values ranging from 17 to $24 \%$ (Cangiano and Bernardello 2005), thus showing more symmetrical karyotypes in Argentinean species then in the Brazilian ones. The variation in A2 values among species from the same geographical areas was generally smaller them between the variation in A2 among species from the two geographical areas.

The karyotypic formulae showed relatively symmetrical karyotypes and a prevalence of metacentric and submetacentric chromosomes in the species of Caesalpinia s.l. studied. This same tendency was observed in Caesalpinioideae by Stebbins (1971), Souza and Benko-Iseppon (2004), Kumari and Bir (1989), and Auler and Battistin (1999). Although the presence of subtelocentric chromosomes in the subfamily is rare (Kumari \& Bir 1989), in the present work one submetacentric pair was observed in C. calycina. According to Stebbins (1971), karyotypic asymmetry is involved in the speciation process, and symmetrical karyotypes are the more ancestral 
condition. Indeed, the A2 describes the variation in chromosome length in a complement, not only the centromere position (Paszko, 2006). Therefore, despite the 12 pairs of metacentric chromosomes in $C$. microphylla, this species had the second largest A2 among the studied species.

Dissimilarities regarding chromosome morphometry were observed in the karyotypes of the species in this study, mainly in the chromosome length and in the presence and location of satellites. Since chromosomes are not rigidly stable structures, chromosome variations play an important role in evolution of practically all species (Souzad \& Benko-Iseppon, 2004).

All five Caesalpinia from Brazil studied herein had satellites visible in the mitotic chromosomes. In C. calycina, C. microphylla, C. ferrea var. leiostachya and C. pulcherrima, we find two pairs of satellites. However ${ }_{2}$ satellites varied in size, position along the arms, as well as in the pairs of chromosomes where they were found. Three pairs of satellites were detected in C. pluviosa var. peltophoroides. The second chromosome pair showed satellites in C. ferrea var. leiostachya, C. microphylla and C. pluviosa var. peltophoroides. The presence of satellites in pair 3 and in pair 4 was verified only in C. pluviosa var. peltophoroides and C. pulcherrima, respectively. Three different Caesalpinia s.l. from Argentina also had satellites observed in their chromosomes (Cangiano \& Bernardello, 2005). Although there is a tendency of maintenance of a similar karyotype pattern among related species, the variations regarding number, shape, position, and length of satellites are frequently observed in plants and have been used as markers (Moscone, 1993). However, these markers can be incorporated or suppressed over the evolutionary process.

C-banded heterochromatin was distributed preferentially in the proximal and telomeric regions in C. ferrea var. leiostachya, C. pluviosa var. peltophoroides, C. pulcherrima and C. calycina, however ${ }_{2}$ no interstitial bands were found. Our findings corroborate those of Guerra (2000) who reported that plant species with small chromosomes do not usually show interstitial heterochromatin. C. pluviosa var. peltophoroides and C. pulcherrima showed small blocks of heterochromatin, whereas $C$. ferrea var. leiostachya and C. calycina showed large blocks of heterochromatin. No C-banding data were obtained for $C$. microphylla, indicating the need to improve the application of this technique for the study of this species. It is noteworthy that this is the first study applying C-banding to species within this genus.

Our results revealed inter-specific differences regarding C-banding patterns and karyomorphology of chromosomes that contribute to our understanding of the karyotypic pathern within Caesalpinia s.l. This study represents a contribution toward an increased knowledge on karyomorphology of Caesalpinia s.1. species. The most Caesalpinia s.l. species have been assigned to reinstated nine segregated genera based on wood anatomy (Gasson et al., 2009). However, our data together with those of Cangiano and Bernadello (2005) are still insufficient for a representative support to these genera. Therefore, we suggest expanding this analysis to other species within Caesalpinia s.l., including at least two species from each new assigned genus. So, this data can be usefull for future evolutionary studies in Caesalpinia.

\section{Acknowledgements}

We would like to thank José Lima Paixão and Fabrício Sacramento Juchum for the cooperation in the collection and botanical identification of the material. Thanks are also due to Patrícia Nayara Caldas, Vanderly Andrade Souza, Graziela Feitosa and Olívia Maria Duarte for their assistance with the cytogenetic techniques. We thank Carter R. Miller and an anonymous reviewer for their helpful comments on the manuscript. Thanks to Marco Antonio Costa for logistic support provided in the Cytogenetics Laboboratory.

\section{References}

Alves, M. A. O., \& Custódio, A. V. C. (1989). Citogenenetics of Leguminosae collected in the state of Ceará. Brazilian Journal of Genetics, 12, 81-92.

Atchison, E. (1951). Studies in the Leguminosae. VI. Chromosome number among tropical woody species. American Journal of Botany, 38, 538-547. http://dx.doi.org/10.2307/2438013

Auler, N. M. F., \& Battistin, A. (1999). Análise do cariótipo de apuleia leiocarpa (Vog.) Macbr. Ciência Rural, 29, 167-169. http://dx.doi.org/10.1590/S0103-84781999000100031

Battaglia, E. (1955). Chromosome morphology and terminology. Caryologia, 8, 179-187.

Beltrão, G. T. D. A., \& Guerra, M. (1990). Citogenética de angiospermas coletadas em Pernambuco-III. Ciência e Cultura, 42, 839-845.

Biondo, E., Miotto, S. T. S., \& Schifino-Wittmann, M. T. (2005). Números cromossômicos e implicações sistemáticas em espécies da subfamília Caesalpinioideae (Leguminosae) ocorrentes na região sul do Brasil. 
Revista Brasileira de Botânica, 28, 797-808. http://dx.doi.org/10.1590/S0100-84042005000400014

Cangiano, M. A., \& Bernardello, G. (2005). Karyotype analysis in Argentinean species of Caesalpinia (Leguminosea). Caryologia, 58, 262-268.

Cruz, C. D. (2006). Programa Genes, Biometria. Viçosa, Brazil: UFV Press.

Cuco, S. M. (2003). Técnicas para a obtenção de preparações citológicas com alta freqüência de metáfases mitóticas em plantas: Passiflora. Passifloraceae) e Crotalaria (Leguminosae). Acta Botanica Brasilica, 17, 363-370. http://dx.doi.org/10.1590/S0102-33062003000300004

Gasson, P., Warner, K., \& Lewis, G. (2009). Wood anatomy of Caesalpinia s.s., Coulteria, Erythrostemon, Guilandina, Libidibia, Mezoneuron, Poincianella, Pomaria and Tara (Leguminosae, Caesalpinioideae, Caesalpinieae). IAWA Journal, 3, 247-276.

Goldblatt, P. (1981). Cytology and the phylogeny of Leguminosae. In: Advances in Legume Systematics (RM Polhill and PR Raven eds). Royal Botanical Gardens, Kew, 2, 427-463.

Guerra, M. (2000). Patterns of distribution heterochromatin in plant chromosomes. Genetics and Molecular Biology, 23, 1029-1041. http://dx.doi.org/10.1590/S1415-47572000000400049

Guerra, M., \& Souz, M. J. (2002). Como observar cromossomos: um guia de técnicas em citogenética vegetal, animal e humana. FUNPEC, Ribeirão Preto.

Huziwara, Y. (1962). Karyotype analysis in some genera of Compositae. VIII. Further studies on the chromosome of Aster. American Journal of Botany, 49, 116-119. http://dx.doi.org/10.2307/2439026

IPN. (2011). The International Plant Name Index.

IUCN. (2011). IUCN Red List of Threatened Species.

Jarolímová, V. (1994). Chromosome counts of some Cuban angiosperms. Folia Geobotanica, 29, 101-106. http://dx.doi.org/10.1007/BF02807781

Jena, S. (2004). Identification of RAPD markers, in situ DNA content and structural chromosomal diversity in some legumes of the mangrove flora of Orissa. Genetica, 122, 217-226. http://dx.doi.org/10.1007/s10709-004-2040-5

Juchum, F. S. (2008). Phylogenetic relationships among morphotypes of Caesalpinia echinata lam. (Caesalpinioideae: Leguminosae) evidenced by trnL intron sequences. Naturwissenschaften, 95, 1085-1091. http://dx.doi.org/10.1007/s00114-008-0424-6

Kumari, S., \& Bir, S. S. (1989). Karyomorphological evolution in Caesalpiniaceae. Journal of Cytology and Genetics, 24, 149-163.

Levan, A., Fredga, K., \& Sandberg, A. A. (1964). Nomenclature for centromeric position on chromosomes. Hereditas, 52, 201-220. http://dx.doi.org/10.1111/j.1601-5223.1964.tb01953.x

Lewis, G. P. (1998). Caesalpinia, a revision of the Poincianella - Erythrostemon group. Kew: Royal Botanic Gardens.

Lewis, G. P. (2005). Legumes of the World. Kew: Royal Botanical Garden.

Moscone, E. A. (1993). Estudios cromosomicos en Capsicum (Solanaceae) II. Kurtzian, 22, 9-18.

Paszko, B. (2006). A critical rewiew and a new proposal of karyotype asymmetry indices. Plant Systematics and Evolution, 258, 39-48.

Pedrosa, A., Schweizer, D., \& Guerra, M. (2000). Cytological heterozygosity and the hybrid origen of sweet Orange (Citrus sinesis (L.) Osbeck). Theoretical and Applied Genetics, 100, 361-367. http://dx.doi.org/10.1007/s001220050047

Shan. F., Yan, G., \& Plummer, J. A. (2003). Karyotype evolution in the genus Boronia (Rutaceae). Botanical Journal of the Linnean Society, 142, 309-320. http://dx.doi.org/10.1046/j.1095-8339.2003.00163.x

Souza, M. G. C., \& Benko-Iseppon, A. M. (2004). Cytogenetics and chromosome banding patterns in Caesalpinioideae and Papilionioideae species of Pará, Amazonas, Brazil. Botanical Journal of the Linnean Society, 144,181-191. http://dx.doi.org/10.1111/j.1095-8339.2003.00230.x

Stebbins, G. L. (1971). Chromosomal evolution in higher plants. London: Addison-Wisley.

Sumner, A. T. (2003). Chromosomes Organization and Function. London: Blackwell Science. 
http://dx.doi.org/10.1111/b.9780631220923.2003.00001.x

Varty, N. (1998). Caesalpinia echinata. In: IUCN 2008. 2008 IUCN Red List of Threatened Species.

Vilatersana, R., Susanna, A., \& Garcia-Jacas, N. (2000). Karyology, generic delineation and dysploidy in the genera Carduncellus, Carthamus and Phonus (Asteraceae). Botanical Journal of Linnean Society, 134, 425-438. http://dx.doi.org/10.1111/j.1095-8339.2000.tb00539.x 